\section{Aborto Induzido em Mulheres de Baixa Renda - Dimensão de um Problema}

\author{
Ignez Ramos Martins* \\ Sarah Hawker Costa** \\ Sylvia Regina da Silva Freitas*** \\ Cristiane Schuch Pinto****
}

Este artigo enfoca a prática de aborto, principalmente aborto induzido entre mulheres de baixa renda. $A$ análise $e$ baseada em dados de pesquisa coletados entre 1984 e 1985 em sete favelas localizadas na área metropolitana do Rio de Janeiro, Brasil (I). Apesar da legislação severa existente, a prática do aborto induzido é muito freqüente.

Entre as mulheres casadas, 21,4 por cento declararam terem praticado aborto induzido. Embora grande parte dos abortos terem sido feitos por médicos, a qualidade dos cuidados nestes procedimentos é questionável, devido ao fato de que, sendo ilegal, na maioria dos casos nâo há possibilidade de supervisão por parte das autoridades de saúde.

A incidência de complicações pós-aborto é muito alta, principalmente nos casos em que $\dot{e}$ praticado por curiosas ou pela propria mulher.

Mais de 60 por cento das mulheres nảo faziam uso de métodos contraceptivos ao engravidar. Cerca de 21 por cento declararam que estavam usando pllula anticoncepcional. Claro está que uma taxa de falha tâo elevada é inaceitável e deve-se ao seu uso incorreto. Tudo isto revela a necessidade urgente de um melhor acesso ao planejamento familiar, oferecido pelos serviços de saúde dentro da concepção de atençâo integral.

São discutidas, também, as conseqüências das leis restritivas em matéria de aborto no Brasil, restriçōes que, na prática, provam ser ineficazes para prevenir a prática do aborto induzido, mas podem ser muito efetivas para ampliar ainda mais as desigualdades sociais já existentes.

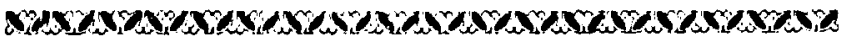

\section{INTRODUÇÃO}

O aborto induzido é muito freqüente no Brasil. Já no início da década de 70 , estimava-se uma ocorrência anual entre $600 \mathrm{mil}$ a 3 milhỏes de abortos induzidos. Estudos mais recentes indicam que de 9 a 22

Cademos de Saúde Pública, RJ, 7 (2): 251-266, abr/jun, 1991
"Prof: Assistente do DEMQS/ Ensp.

* Pesq: Associada do DEMQSI Ensp.

* *Pesq: Auxiliar do DEMQS/ Ensp.

****Prof: Aux, do DEMQS/

Ensp.

(1) "Family Planning Practice in a low Income Community in Rio de Janeiro: 1984-1985", pesquisa que contou com o apoio do "Special Programme of Research, Development and $R e-$ search Training in Human Reproduction" da Organizaçäo Mundial de Saúde. 
por cento das mulheres relatam terem tido um ou mais abortos provocados.

A própria variação destes relatos e estimativas reflete o quanto se desconhece a verdadeira magnitude do problema.

A legislação brasileira, nessa matéria, é extremamente rígida. S $\delta$ é permitido o aborto, dito terapêutico, para salvar a vida da mãe ou, então, quando a gravidez resulta de estupro. Neste último caso, dada a exigência de autorização judicial, a morosidade habitual dos processos inviabiliza, quase sempre, a intervenção em tempo hábil.

$\mathrm{Na}$ ausência de um programa nacional de planejamento familiar efetivo, o acesso aos métodos reversiveis de anticoncepção restringe-se, quase que exclusivamente, à pilula, para a maioria das mulheres. Esta é quase sempre adquirida nas farmácias sem prescrição, e o seu uso é feito pela maioria das usuárias sem supervisão médica (COSTA et al., 1989). Como conseqũência, muitas mulheres expöem-se a riscos desnecessários à saúde, pelo uso inadequado e incorreto da pílula. Adicionalmente são altas a descontinuidade e as falhas do método, resultando em gravidez não-desejada e, não raro, na indução do aborto, apesar das restriçöes legais.

O principal efeito dessas medidas restritivas, no entanto, é justamente exacerbar as desigualdades sócio-econômicas existentes entre nós. Na maioria das cidades, existem serviços de bom padrão, aos quais as mulheres que podem pagar recorrem para induzir o aborto sem risco excessivo. No entanto, essa nāo $\varepsilon$ a realidade para muitas mulheres que, pela sua pobre$\mathrm{za}$ ou por razōes de constrangimento social, terminam recorrendo a pessoal nāo-treinado, sendo o aborto praticado em precárias condições de higiene. Muitas vezes a própria mulher tenta primeiro induzir o aborto, usando procedimentos perigosos como a introdução de talos, agulhas de crochê, uso de permanganato, soda cáustica etc.

Não é de admirar que estes abortos, realizados em condições adversas, sejam seguidos por complicaçōes severas que demandam atenção médica e, nāo raro, levam à morte (Henshaw, 1990).

Nos hospitais de emergência do Município do Rio de Janeiro, os abortos representam cerca de 30 por cento das internações obstétricas. Um estudo realizado em São Paulo não só confirma a gravidade do problema, como ressalta o aumento de internaçōes por complicações de aborto nos últimos anos, especialmente entre adolescentes (Schor, 1984).

Mesmo estimando-se um sub-registro ao redor de 50 por cento, o aborto ocupa o quarto lugar nas causas de mortalidade materna, representando 11 por cento dessas mortes (Siqueira et al., 1984). 
Em um estudo sobre mortalidade materna no período de 1978 a 1987, realizado no hospital de emergência Miguel Couto, do Rio de Janeiro, foi verificado um aumento na ordem de 172 por cento na mortalidade relacionada ao aborto, que passou de 85 por $100 \mathrm{mil}$ nascidos vivos em 1978 para 231 por 100 mil nascidos vivos em 1987 (Laguardia, K, 1989).

Além da preocupação com os riscos e sofrimentos a que estão expostos estas mulheres, há que atentar, também, para os custos sociais dos gastos médicoshospitalares despendidos no tratamento das complicações pós-aborto.

Dada a magnitude do problema, da qual conhecemos apenas a ponta do iceberg, é imperioso estudar os determinantes dessa prática, assim como as condiçōes em que ela ocorre.

Nesse sentido, o aborto induzido foi uma das áreas focalizadas na pesquisa sobre "Prática de Planejamento Familiar em Mulheres de Baixa Renda no Município do Rio de Janeiro", realizada pela Escola Nacional de Saúde Pública nos anos de 1984 e 1985. Este artigo analisa os resultados relativos à questão do aborto, especialmente o aborto induzido.

\section{METODOLOGIA}

A Metodologia adotada nesta pesquisa foi descrita no artigo "A Prática de Planejamento Familiar em Mulheres de Baixa Renda no Município do Rio de Janeiro", publicada em Cadernos de Saúde Pública, 5 (2) $187-206$, abr/jun, 89.

Constituiu um estudo seccional por amostragem estratificada aleatória em que foram entrevistadas 1783 mulheres de 15 a 49 an os de idade, independentemente da situação conjugal. A área em questão encontra-se sob a responsabilidade do Centro de Saúde Escola Germano Sinval Faria/Ensp que, por ocasiäo da pesquisa, não oferecia, ainda, serviços de Planejamento Familiar, os quais só posteriormente foram implantados.

$O$ instrumento utilizado foi um questionário pré-codificado, incluindo algumas questōes abertas.

A seçẩo do questionário sobre aborto foi respondida por todas as mulheres que já haviam estado grávidas. Devido à suscetibilidade do tema, as entrevistadoras foram especialmente treinadas para a aplicação desta parte do questionário. O objetivo principal era obter informaçōes sobre a ocorrência de aborto induzido; no entanto, foram feitas algumas questōes sobre abortos espontâneos, atentando para a possibilidade de abortos induzidos serem relatados como espontâneos, e também para poder comparar os resultados com os de outros estudos, que abordam o assunto de forma global, sem distinguir os abortos espontâneos dos provocados. 
As mulheres foram questionadas sobre a história e número de abortos e, de uma maneira mais detalhada, sobre o último aborto. Não houve a intenção de estudar $a$ incidência de aborto, já que, para isto, o número de mulheres a entrevistar teria de ser muitíssimo maior. Estima-se que seria necessário entrevistar $100 \mathrm{mil} \mathrm{mu-}$ lheres entre 15 a 49 anos para termos uma amostra de 959 mulheres, declarando ter tido um aborto induzido no ano precedente.

Com a preocupação de evitar que conclusőes equivocadas como, por exemplo, um excesso de abortos induzidos ser atribuído a hospitais de emergência, foi feita uma distinção entre o processo de indução do aborto e o momento em que foi apenas completado.

Mesmo tomados todos os cuidados, pela própria natureza do tema, estima-se que os dados estejam subestimados.

$\mathrm{Na}$ Tabela I, vemos algumas características sócioeconômicas e demográficas das mulheres entrevistadas.

\section{Prevalência de História de Aborto}

Como demonstra a Tabela II, foi encontrada uma alta prevalência de história de aborto entre as mulheres de 15 a 49 anos. Trinta e um por cento relataram já terem abortado, sendo que 16,9 por cento dos casos foram induzidos. Entre as casadas, a proporçāo de mulheres com história de aborto induzido chega a 21,4 por cento, entretanto, quando focalizamos apenas as mulheres que haviam engravidado, esta taxa alcança 23,5 por cento.

A proporção de mulheres com história de aborto foi, inclusive, mais elevada do que a encontrada em levantamento realizado em 1985 entre as gestantes freqũentando o serviço de pré-natal do Centro de Saúde Escola Germano Sinval Faria, quando somente 10,9 por cento relataram ter tido pelo menos um aborto induzido e 18,4 por cento espontâneo (Garcia, 1990).

Cerca de um quarto das gestaçōes resultaram em aborto, como pode ser visto na Tabela III. Esta relaçảo e mais alta do que a encontrada em um estudo feito na América Latina (Gaslonde, et al., 1981), do que a encontrada no sul do Brasil, onde somente cerca de 11 por cento terminaram em aborto (Rodrigues et al., 1981).

\section{Aborto Espontâneo}

Do total de entrevistadas, 17 por cento mencionaram terem tido pelo menos um aborto espontâneo, como pode ser visto na Tabela $\Pi$. Entre as solteiras, 8,2 por cento das gestaçöes resultaram em aborto es- 
pontâneo; entre as casadas, este percentual foi de dez por cento. A diferença encontrada entre solteiras e casadas foi bem maior em relação ao aborto induzido, como discutiremos adiante.

\section{TABELA I}

Características Sócio-econômicas das Mulheres de $15-49$ anos

Caracterfsticas

N: de Mulheres

$\%$

Renda Familiar

$<1$ salário mfnimo

128

7,2

1-3 salários mf́nimos

984

55,2

3-5 salários mf́nimos

386

21,6

$>5$ salários mínimos

212

Sem informaçăo

Ntuel de Instrução

Analfabetos

1: grau incompleto

- grau incompleto

61,2

$>$ 2: graul

Sem informação

Trabalho

Trabalha fora

Trabalha em casa

Nåo trabalha

Regiāo de Origem

Norte 14

Nordeste

Sul

Sudeste

8

8,2

Sem informação

1208

Fonte: Cadernos de Salde Páblica, RJ, 5 (2): 187-206, abr/jun, 1989

Como pode ser visto na Figura I, "Aborrecimentos" foi a principal causa apontada para o aborto. Menos de 15 por cento dos abortos foram atribuídos a problemas de saúde. Em "outras razōes" estão agrupados desde "desejos frustrados de comer alguma coisa", até violentas agressōes físicas que foram vítimas essas mulheres.

Cadernos de Saude Pública, RJ, 7 (2): 251-266, abr/jun, 1991 


\author{
TABELA II
}

Mulheres de 15-49 Anos com História de Aborto, por

Tipo de Aborto, Situação Conjugal e Faixa Etária

\begin{tabular}{|c|c|c|c|c|c|}
\hline \multirow{3}{*}{$\begin{array}{l}\text { História } \\
\text { e Tipo } \\
\text { de Aborto }\end{array}$} & \multirow{3}{*}{$\begin{array}{c}\text { Todas } \\
\text { as } \\
\text { Idade } \\
\%\end{array}$} & \multicolumn{4}{|c|}{ Idade na Entrevista } \\
\hline & & $\leqslant 19$ & $20-29$ & $30-39$ & $\geqslant 40$ \\
\hline & & $\%$ & $\%$ & $\%$ & $\%$ \\
\hline \multicolumn{6}{|l|}{ Todas as mulheres } \\
\hline Provocado & 16,9 & 3,9 & 13,4 & 21,6 & 29,6 \\
\hline Espontâneo & 16,2 & 2,3 & 12,1 & 20,8 & 31,5 \\
\hline Nunca abortou & 68,5 & 91,2 & 74,1 & 60,8 & 46,3 \\
\hline Total de mulheres & 1783 & 308 & 669 & 495 & 311 \\
\hline \multicolumn{6}{|l|}{ Ja engravidou } \\
\hline Provocado & 23,5 & 20,0 & 18,6 & 24,1 & 31,7 \\
\hline Espontâneo & 22,6 & 11,7 & 16,7 & 23,2 & 33,8 \\
\hline Nunca abortou & 56,1 & 55,0 & 64,2 & 56,3 & 42,4 \\
\hline Total de mulheres & 1278 & 60 & 484 & 444 & 290 \\
\hline \multicolumn{6}{|l|}{ Casadas atualmente } \\
\hline Provocado & 21,4 & 11,9 & 15,4 & 23,8 & 30,6 \\
\hline Espontâneo & 21,2 & 10,2 & 15,2 & 22,8 & 32,8 \\
\hline Nunca abortou & 61,8 & 78,7 & 72,3 & 57,3 & 46,0 \\
\hline Total de mulheres & 1163 & 59 & 448 & 408 & 248 \\
\hline \multicolumn{6}{|l|}{ Solteiras } \\
\hline Provocado & 6,1 & 2,0 & 7,8 & 10,0 & 25,0 \\
\hline Espontâneo & 3,9 & 0,4 & 4,8 & 10,0 & 16,7 \\
\hline Nunca abortou & 90,0 & 97,6 & 87,4 & 80,0 & 58,3 \\
\hline Total de mulheres & 538 & 248 & 206 & 60 & 24 \\
\hline
\end{tabular}

Observaçāo: Algumas mulheres tiveram tanto abortos espontâneos como provocados, por essa razăo as colunas não somam cem por cento. 


\section{TABELA III}

Relação de Abortos Totais Espontâneos e Induzidos por Gestações, Segundo a Situação Conjugal e Faixa

\section{Etária}

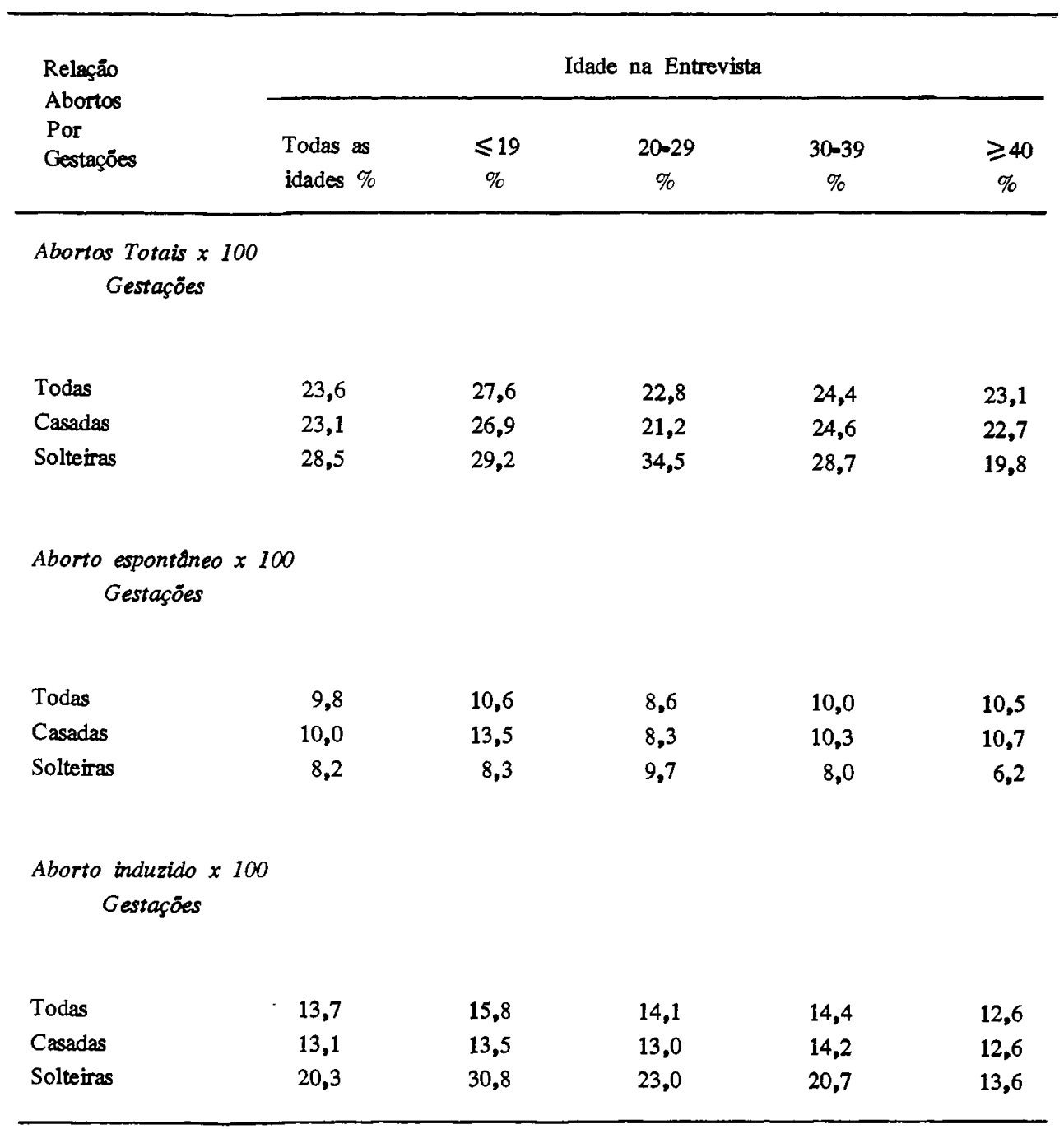




\section{ANÅ LISE}

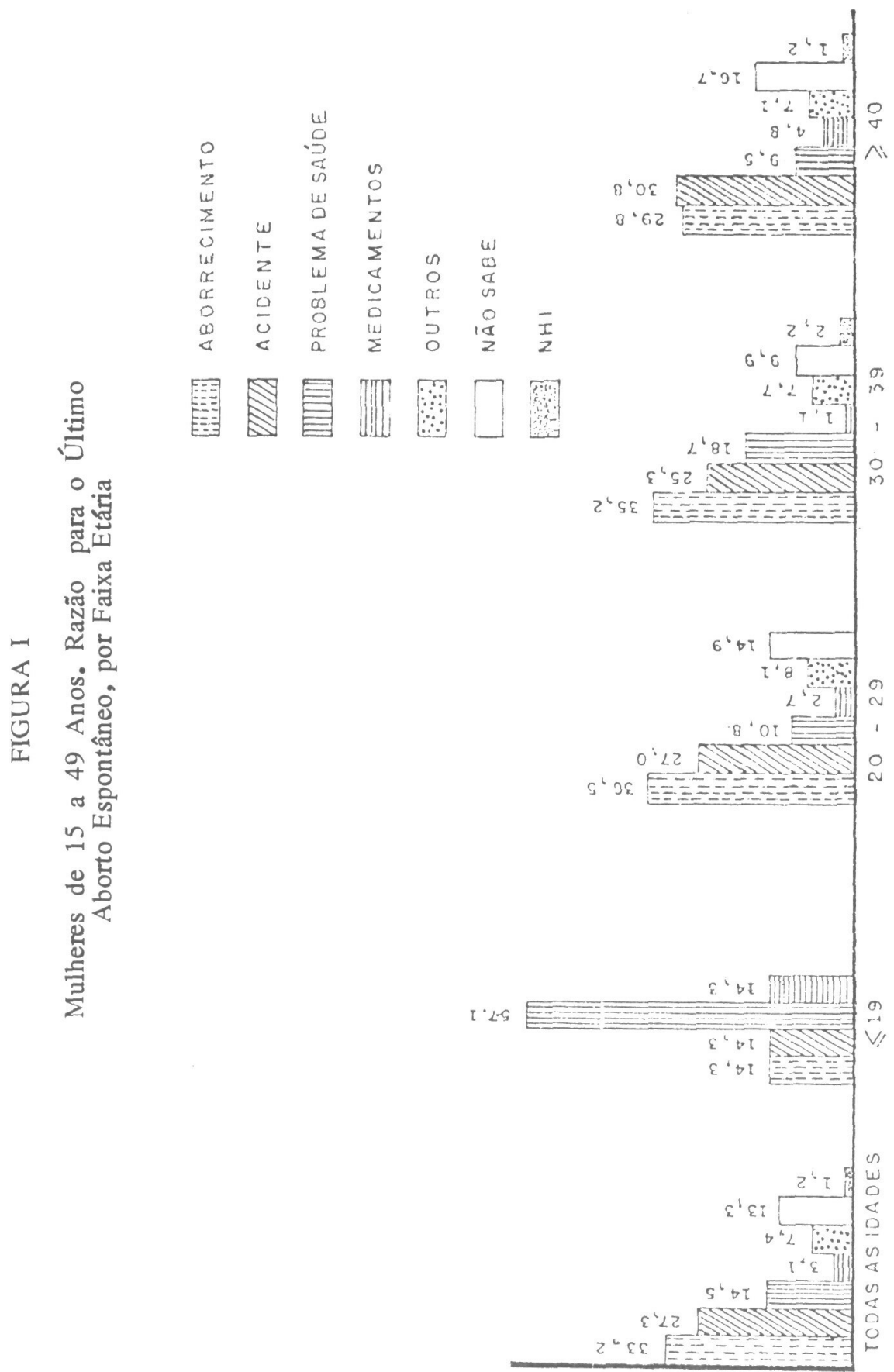


A questão da violência como causa para as perdas fetais também foi ressaltada em outra pesquisa realizada em 1983, na favela da Rocinha, no Rio de Janeiro. Este estudo revelou que 20 por cento dos abortos foram atribuídos a um "susto", "sustos" estes que, após uma investigaçāo mais cuidadosa, traduziram-se na maior parte das vezes, por espancamentos por parte dos parceiros. Estes casos poderiam ser agregados aos 15 por cento dos abortos atribuídos a brigas com os maridos (Valladares et al., 1987).

\section{Aborto Induzido}

Do total de abortos, 50,9 por cento foram induzidos, numa média de 2,1 abortos induzidos por mulheres com história de indução de aborto.

A situação conjugal é relevante, já que a probabilidade das mulheres solteiras induzirem o aborto $\varepsilon$ bem maior do que entre as casadas, como pode ser visto na Tabela III.

$\mathrm{Na}$ Figura II, pode-se verificar que as razōes de ordem econômica predominam, na justificaçăo do aborto. Para quase todos os grupos etários, exceto para as mulheres de 20 a 29 anos para quem "năo queria ter filho na ocasiäo" é a principal razão, as razỏes financeiras se destacam. E interessante assinalar que 16,4 por cento das mulheres declararam que induziram o aborto por não quererem definitivamente ter mais filhos. A instabilidade conjugal $\varepsilon$ outro motivo freqüente. Problemas de saúde e indicação médica como razão para a indução de aborto aparecem com maior expressão no grupo etário de $40 \mathrm{a} 49$ anos.

Claro está que, embora estas tenham sido as razöes mencionadas em primeiro lugar pelas mulheres, $\varepsilon$ razoável supor que, se fosse feita uma investigação mais profunda, estas justificativas seriam mais bem explicitadas ou outras subjacentes viriam à tona. A resposta "Nāo queria ter filho na ocasiāo", por exemplo, poderia estar relacionada a razōes econômicas, problemas conjugais, trabalho etc. De qualquer maneira, é bem diferente de "Não querer ter mais filho", que pode implicar o desejo de optar, no futuro, pela esterilização, ao contrário das primeiras, para as quais um método reversível seria a opção adequada.

Analisando as Tabelas IV e $\mathrm{V}$ pode-se verificar que a maioria dos abortos foi induzida por médicos, em consultórios ou hospitais, através de curetagem. Cerca de dez por cento foram feitos por curiosas que, para tanto, valem-se principalmente da sonda. Dezoito por cento dos abortos foram induzidos pelas próprias mulheres, valendo-se de medicamentos, sondas e metodos tradicionais diversos, que podem significar práticas estranhas, como "beber três goles de água e ficar Cadernos de Saúde Pública, RJ, 7 (2): 251-266, abr/jun, 1991 
pulando", até procedimentos altamente perigosos e contundentes, como a introdução de agulhas e talos, ou a utilização de permanganato de potássio e de substâncias cáusticas.
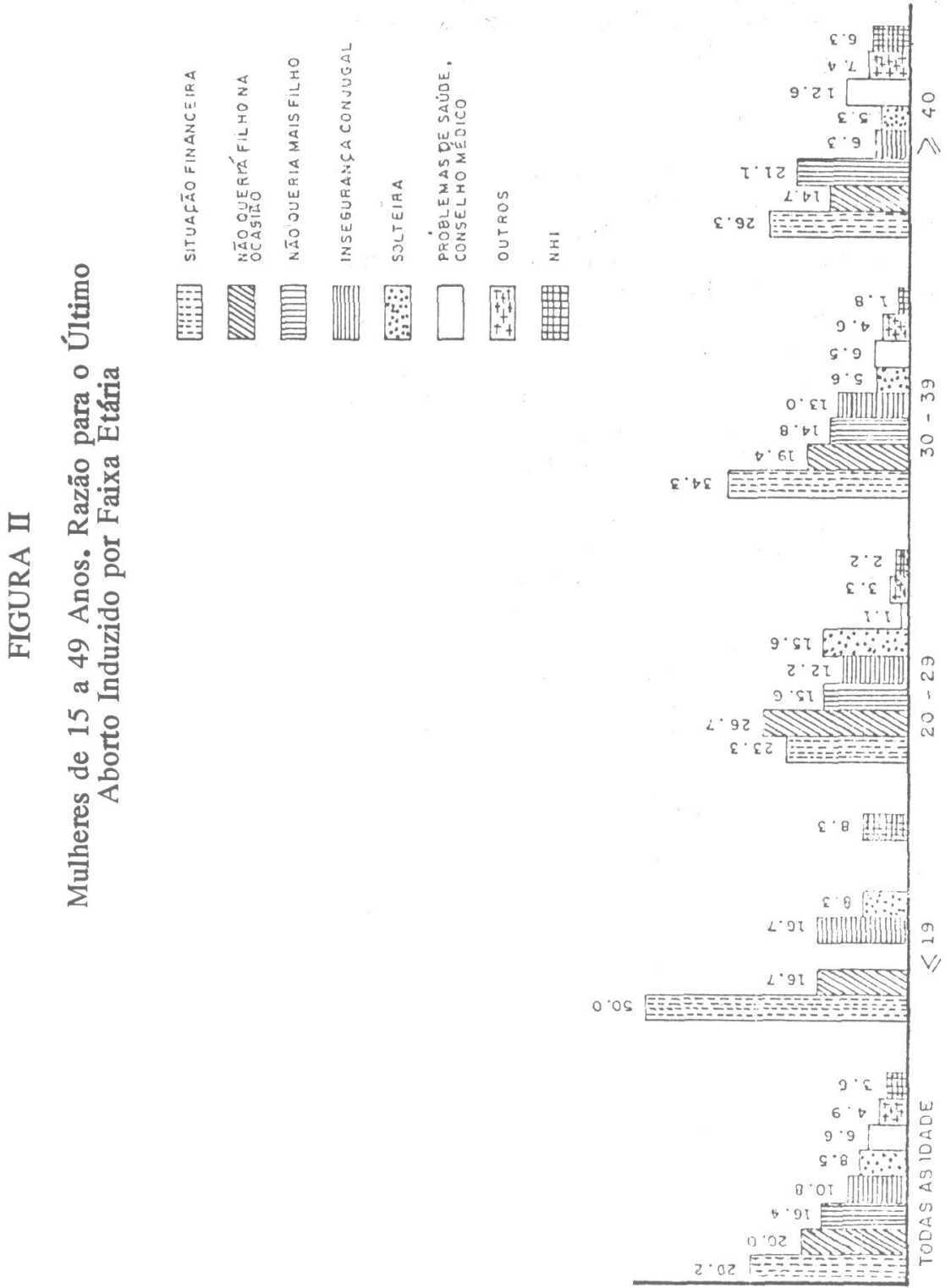


\section{TABELA IV}

Distribuição Percentual das Mulheres de 15-49 Anos com História de Aborto

Induzido, por Algumas Características

\begin{tabular}{|c|c|}
\hline Caracteristicas & $\%$ \\
\hline \multicolumn{2}{|l|}{ Idade na entrevista } \\
\hline$\leqslant 19$ & 3,9 \\
\hline $20-29$ & 29,5 \\
\hline $30-39$ & 35,4 \\
\hline$\geqslant 40$ & 31,1 \\
\hline \multicolumn{2}{|l|}{ Método que usava antes de engravidar } \\
\hline Pflula & 21,3 \\
\hline Métodos naturais & 5,6 \\
\hline Outros & 6,9 \\
\hline Nenhum & 62,3 \\
\hline NHI & 3,9 \\
\hline \multicolumn{2}{|l|}{ Quem Fez } \\
\hline Médico & 65,5 \\
\hline Curiosa ou Parteira & 9,8 \\
\hline A própria & 18,0 \\
\hline Outros ou NHI & 6,6 \\
\hline \multicolumn{2}{|l|}{ Local } \\
\hline Hospital & 6,9 \\
\hline Clfinica ou Consultório & 58,0 \\
\hline Casa da parteira ou curiosa & $.8,2$ \\
\hline Residência da Mulher & 22,0 \\
\hline Outro & 4,9 \\
\hline \multicolumn{2}{|l|}{ Tipo de Procedimento } \\
\hline Curetagem & 62,1 \\
\hline Medicação & 13,3 \\
\hline Sonda & 11,0 \\
\hline Outro & 9,6 \\
\hline NHI & 4,0 \\
\hline \multicolumn{2}{|l|}{ Complicaçäo } \\
\hline $\operatorname{Sim}$ & 22,3 \\
\hline Não & 73,8 \\
\hline NHI & 3,9 \\
\hline \multicolumn{2}{|l|}{ Tempo de Gestaçäo } \\
\hline 1 mês & 22,9 \\
\hline $2-3$ meses & 63,3 \\
\hline $4-6$ meses & 8,9 \\
\hline NHI & 4,9 \\
\hline Total de mulheres & 305 \\
\hline
\end{tabular}


Mulheres de 15 a 49 Anos, Último Aborto Induzido, Procedimento Usado Segundo Quem Fez o Aborto

\begin{tabular}{|c|c|c|c|c|c|c|}
\hline Procedimento & $\begin{array}{c}\text { Total } \\
\%\end{array}$ & $\begin{array}{c}\text { Médico } \\
\%\end{array}$ & $\begin{array}{c}\text { Curiosa } \\
\%\end{array}$ & $\begin{array}{c}\text { Própria } \\
\text { Mulher } \\
\%\end{array}$ & $\begin{array}{c}\text { Outro } \\
\%\end{array}$ & $\begin{array}{c}\text { S/Inform. } \\
\%\end{array}$ \\
\hline Curetagem & 62,1 & 92,5 & 6,9 & - & - & 18,2 \\
\hline Medicamentos & 13,3 & 3,0 & 17,3 & 41,4 & 70,0 & - \\
\hline Sonda & 11,0 & 1,0 & 69,0 & 17,0 & 20,0 & - \\
\hline Outros & 9,6 & 2,5 & 3,4 & 41,6 & 10,0 & - \\
\hline S/Informação & 4,0 & 1,0 & 3,4 & - & - & 81,8 \\
\hline \multirow{2}{*}{\multicolumn{7}{|c|}{$\begin{array}{l}\text { Base: Mulheres de } \\
15-49 \text { anos } \\
\text { cm história } \\
\text { de aborto induzido }\end{array}$}} \\
\hline & & & 30 & 55 & 10 & 11 \\
\hline \% Complicaçöes & 22,3 & 16,1 & 56,7 & 29,1 & 30,0 & - \\
\hline
\end{tabular}

Dos abortos induzidos, 22,3 por cento tiveram complicaçōes, demandando assistência médica, sendo que 14,6 por cento resultaram em intemação.

Em estudos realizados em outras partes do Brasil, entre 1981 e 1982, foi constatada uma grande variaçäo nos resultados relativos às complicaçốes pós-aborto, incluindo os espontâneos. $\mathrm{Na}$ regiảo Sudeste foram relatados 72 por cento de complicaçöes; já no Piauí foram encontrados apenas 23 por cento (Rodrigues et al., 1982). Em outro estudo, realizado em Sāo Paulo, em 1978, foi constatada a ocorrência de complicação em cerca de 40 por cento dos abortos (Nakamura, et al., 1979).

Vale ressaltar que, na atual pesquisa, os resultados sobre complicaçoes restringem-se aos abortos induzidos, enquanto que nos estudos acima referidos todas. as perdas fetais foram consideradas. É preciso lembrar que as mulheres não somente tendem a esconder informaçöes sobre o aborto induzido, como também, em muitos casos, procuram evitar recorrer aos serviços de assistência médica quando surgem problemas, até mesmo para proteger o responsável pelo aborto.

Cerca de 50 por cento dos abortos induzidos por curiosas resultaram em complicaçōes, como pode ser visto na Tabela VII. A relativamente baixa ocorrência 
de complicaçōes, quando a própria mulher induz o aborto, poderia ser atribuída ao fato de que alguns dos métodos utilizados, como chás e medicamentos, sejam in 6 cuos para tal fim, e que, na verdade, atrasos menstruais tenham sido rotulados de abortos.

\section{TABELA VI}

Ocorrência de Complicação Após o Último Aborto Induzido nas Mulheres de 15 a 49 Anos, Segundo Algumas Características

\begin{tabular}{|c|c|c|c|c|}
\hline Caracterfsticas & $\begin{array}{c}\text { C/Complicaçăo } \\
\%\end{array}$ & $\begin{array}{c}\text { S/Complicaçăo } \\
\%\end{array}$ & $\begin{array}{c}\text { NHI } \\
\%\end{array}$ & $\begin{array}{c}\text { N: de } \\
\text { Mulheres }\end{array}$ \\
\hline \multicolumn{5}{|l|}{ Quem Fez } \\
\hline Médico & 16,1 & 83,4 & 0,5 & 199 \\
\hline Parteira/Curiosa & 56,7 & 43,3 & - & 30 \\
\hline Própria & 29,1 & 70,9 & - & 55 \\
\hline Outros & 30,0 & 70,0 & - & 10 \\
\hline NHI & - & - & 100,0 & 11 \\
\hline \multicolumn{5}{|l|}{ Onde Fez } \\
\hline Hospital & 47,6 & 47,6 & 4,8 & 21 \\
\hline Consultório & 11,4 & 88,6 & - & 176 \\
\hline $\begin{array}{l}\text { Casa da Parteira ou } \\
\text { Curiosa }\end{array}$ & 52,0 & 48,0 & - & 25 \\
\hline Residencia & 34,3 & 65,7 & - & 67 \\
\hline Farmácia & 40,0 & 60,0 & - & 5 \\
\hline NHI & - & - & 100,0 & 11 \\
\hline \multicolumn{5}{|l|}{ Como Abortou } \\
\hline Curetagem & 18,0 & 82,0 & - & 189 \\
\hline Remédio oral e injeçăo & 26,3 & 73,7 & - & 38 \\
\hline Sonda & 50,0 & 50,0 & - & 34 \\
\hline Outras & 21,4 & 78,6 & - & 28 \\
\hline NHI & 6,3 & 18,7 & 75,0 & 16 \\
\hline \multicolumn{5}{|l|}{ Tempo de Gestação } \\
\hline Ate $1 \mathrm{mss}$ & 8,6 & 91,4 & - & 70 \\
\hline 2 a 3 meses & 23,8 & 76,2 & - & 193 \\
\hline 4 a 6 meses & 56,6 & 44,4 & - & 27 \\
\hline NHI & 6,7 & 13,3 & 80,0 & 15 \\
\hline Total & 22,3 & 73,8 & 3,9 & 305 \\
\hline
\end{tabular}


Como era de esperar, as complicaçōes aumentam com o tempo de gestaçäo; do terceiro mês em diante, mais da metade resultaram em complicaçōes. É preocupante verificar que mais de 20 por cento destes abortos foram provocados pela introdução de sondas, método preferencialmente utilizado por curiosas ou pela própria mulher.

A Tabela VII evidencia que, ao engravidarem, 62,3 por cento das mulheres nāo estavam usando método contraceptivo e que 21 por cento tomavam pílula. Não é surpreendente esta altíssima taxa de "falha" do método, se a confrontarmos com o resultado de uso incorreto da pilula, já que cerca de 23 por cento destas mulheres não tomavam pillulas de maneira adequada pelas razões as mais variadas (Costa, et al., 1990).

\section{TABELA VII}

Mulheres de 15-49 Anos com Historia de Aborto Induzido, Segundo Método Usado Quando Engravidou, por Faixa Etária (último aborto)

\begin{tabular}{|c|c|c|c|c|}
\hline \multirow{3}{*}{ Método } & \multirow{3}{*}{$\begin{array}{c}\text { Total } \\
\% \\
\end{array}$} & \multicolumn{3}{|c|}{ Faixa Etária } \\
\hline & & $15-29$ & $30-39$ & $40-49$ \\
\hline & & $\%$ & $\%$ & $\%$ \\
\hline P Ohulas & 21,3 & 23,5 & 27,8 & 11,6 \\
\hline Outros Métodos & 6,9 & 2,0 & 10,2 & 8,9 \\
\hline Métodos Naturais & 5,6 & 2,9 & 4,6 & 9,5 \\
\hline Năo Usava & 62,3 & 68,6 & 56,5 & 62,1 \\
\hline NHI & 3,9 & 2,9 & 0,9 & 8,4 \\
\hline
\end{tabular}

Base: mulheres

de 15 a 49 anos com

história de

aborto induzido

305

102

108

95

\section{CONCLUSÕES}

Este trabalho mostra não somente a elevada prevalência de aborto induzido em mulheres residentes em favelas do Rio de Janeiro, como também a gravidade dessa prática pelas circunstâncias em que ocorre.

Mesmo que a maioria dos abortos seja induzida por médicos, isto não garante a qualidade dos mesmos, 
já que a própria situação de ilegalidade impossibilita a supervisão pelas autoridades de saúde.

Não é surpreendente a alta ocorrência de complicaçõs de abortos induzidos por curiosas, complicações estas que aumentam a demanda nos serviços de saúde, resultando, nāo raro, em morte.

$\mathrm{Na}$ ausência de um programa efetivo de atenção integral à saúde que ofereça um acesso real aos meios de contracepção, freqüentemente, a mulher, particularmente a de baixa renda, defronta-se com uma gravidez indesejada. Pressionada por inúmeros fatores, que podem ser de poder aquisitivo, instabilidade conjugal, dificuldade de conciliar a criação de um filho, face a inexistência de creches, com a necessidade de trabalhar, a mulher recorre ao aborto, solução dramática, pelo menos a nível emocional.

$\mathrm{Se}$ a desigualdade social quanto ao acesso aos meios de contracepção já existe, essa desigualdade também existe quando a mulher pobre decide fazer um aborto, já que o alto custo da intervenção de boa qualidade pode fazer com que a mesma recorra a uma curiosa ou provoque ela mesma o aborto, expondo-se a um alto risco.

Se os resultados desta pesquisa mostram a necessidade de ampliar o acesso real à contracepção, por outro lado fica claro que há urgência em estudar, criteriosamente, as conseqüências reais da legislação restritiva em matéria de aborto, pois, como ficou evidente, no lugar de impedir a sua ocorrência, termina resultando no agravamento do problema e contribuindo para um excesso de riscos à saúde e para o aumento da mortalidade materna, ampliando, deste modo, as já tão grandes injustiças sociais existentes.

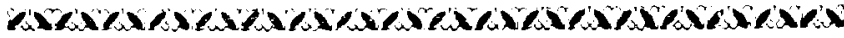

This paper examines the practice of abortion, especially induced abortion among low income women. The discussion is based on survey data collected between 1984 and 1985 in seven slum communities (favelas) situated in the metropolitan area of Rio de Janeiro, Brazil. Despite restrictive law, induced abortion is extremely frequent. Among married women 21.4 per cent reported experience of induced abortion. Most abortions were performed by physicians, however the quality of care of these procedures can be questioned since almost all induced abortions are illegal there is no possible supervision by health authorities.

The incidence of post-abortion complication is very high, especially for those performed by traditional midwifes or by the woman herself.

Cadernos de Saúde Pública, RJ, 7 (2): 251-266, abr/jun, 1991 
More than 60 per cent of the women were not using contraception at the time of pregnancy. About, 21 per cent reported that they were using the pill. Such a high pill failure rate is inacceptable, and probably was related to incorrect use. This points to the need for a better access to family planning care within the health services.

The consequences of the restrictive abortion laws in Brazil are also discussed. Restrictions that in practice prove to have little impact on the practice of induced abortion, appear to be very effective in broading even more the social-economic innequalities.

\section{REFERÊNCIAS BIBLIOGRÁFICAS}

COSTA, S.H.; MARTINS, I.R.; PINTO, C.S.; FREITAS, R.S. "A Prática de Planejamento Familiar em Comunidades de Baixa Renda". Cadernos de Salde Páblica, Rio de Janeiro, vol, 4, abr. jun., 1989.

COSTA, S.H.; MARTINS, I.R.; PINTO, C.S.; FREITAS, S.R. "Family Planning Practice Among Low-Income Women in Rio de Janeiro: 1984 - 1985" International Family Planning Perso pectives, Vol. 16, number 1, March, 1990.

GARCIA, M.G.R. "Atenção à Gestante no Centro de Safide Escola Germano Sinval Faria" (Comunicaçăo Pessoal).

GASLONDE, S. "Investigación sobre el aborto en America Latina" Estudios de Poblacibn, Bogotá, VI tomo II, 1976 p.439-449.

HENSHAW, S.K. "Induced Abortion" a World review 1990, International Family Planning Perspectives, Vol, 16, number 1, June, 1990.

LAGUARDIA, K. "A Ten Years Review of Maternal Mortality in the Municipal Hospital in Rio de Janeiro: A Cause for Concern". Joumal of Obstetrics and Gynaecology (apresentado para publicação, 1990).

NAKA MURA, M. et al. São Paulo State Contraceptive Prevalence; Survey Final Report. Campinas, Universidade Católica, 1979.

RODRIGUES, W. et al. Pesquisa sobre Salide Matemo-Infantil e Planejamento Familiar, Piaul, 1981. Benfam, 1982.

RODRIGUES, W. et al. Pesquisa sobre Salde Materno-Infantil e Planejamento Familiar, Regiāo Sul, 1981. Benfam, 1982.

SHOR, N. Aborto como Questāo de Saúde Püblica. Estudo de Demanda de Mulheres que Recorrem ao Hospital por Complica çöes de Aborto. Tese de doutorado apresentada à Faculdade de Saf́de Pública da Universidade de São Paulo, 1984.

SIQUEIRA, A.A.; TANAKA, A.C.A.; SANTANA, R.A. et al. "Mortalidade Materna no Brasil", 1980. Revista de Salude Pablica, São Paulo, 18: 448-65, 1984.

VALLADARES, D.P.; ZELASCHI, S.S.; GIFFIN, K.; LOVISOLO, H.; Mulheres Participação e Salde: uma experiência, Rio de Janeiro: Faculdade Latino Americana de Ciências Sociais, Programa Brasil, 1987. 